\title{
Knowledge and selected variables as determinants of the quality of life and general health of patients with rheumatoid arthritis
}

\author{
Aleksandra Pytel ${ }^{1,2, A-F}$, Iwona Demczyszak ${ }^{1, B, C, E}$, Edyta Sutkowska ${ }^{1, C, E, F,}$ \\ Joanna Rosińczuk ${ }^{2, E, F}$, Izabela Kuberka ${ }^{2, B, C, E}$, Aleksandra Kołtuniuk ${ }^{2, B-E}$ \\ ${ }^{1}$ Department of Medical Rehabilitation, Wroclaw Medical University, Poland \\ ${ }^{2}$ Department of Nervous System, Wroclaw Medical University, Poland \\ A - research concept and design; $\mathrm{B}$ - collection and/or assembly of data; $\mathrm{C}$ - data analysis and interpretation; \\ $D$ - writing the article; $E$ - critical revision of the article; $F$ - final approval of the article
}

Address for correspondence

Aleksandra Pytel

E-mail: olapyte@@onet.eu

Funding sources

None declared

Conflict of interest

None declared

Received on November 15, 2015

Reviewed on November 7, 2016

Accepted on February 9, 2017

\begin{abstract}
Background. Rheumatoid arthritis (RA) is an incurable disease resulting in progressive disability, which is associated with the loss of productivity and the inability to earn money, which might lead to a financial burden on the patient's family. Undoubtedly, the clinical picture of the disease and its consequences lead to the reduction of the quality of life.
\end{abstract}

Objectives. The aim of this study is to evaluate the influence of selected factors on the subjective assessment of the quality of life and general health of patients with RA.

Material and methods. The study was conducted among 270 patients with RA treated at the Department of Rheumatology and Internal Medicine. The quality of life and general health were assessed with the use of the SF-36 and the GHQ-30 questionnaires.

Results. In the study group, a statistically significant correlation between the results of the SF-36 and the GHQ-30 questionnaires was observed. It has been shown that the level of role limitations due to physical health problems (RP) is mostly affected by interpersonal relationships based on GHQ-30 questionnaire $(p=0.002)$, general health (GHQ-30) $(p=0.001)$ and subjective health condition (SF-36) $(p<0.001)$. In contrast, general health (GHQ-30) is positively affected by education $(p=0.003)$ and professional activity $(p=0.001)$, and negatively affected by a positive family history of $R A(p=0.002)$, frequent hospitalization $(p=0.008)$ and poor subjective health condition $(p<0.001)$.

Conclusions. People with poor subjective health condition are characterized by more limited activity due to physical health and lower general health condition. General health (GHQ-30) in patients with rheumatoid arthritis is influenced by education, place of residence, professional work, family history of RA and subjective health status.

Key words: quality of life, rheumatoid arthritis (RA), SF-36 questionnaire, General Health Questionnaire (GHO)

DOI

10.17219/acem/68900

Copyright

Copyright by Author(s)

This is an article distributed under the terms of the

Creative Commons Attribution Non-Commercial License

(http://creativecommons.org/licenses/by-nc-nd/4.0/) 


\section{Introduction}

The quality of life is a multidimensional concept, varying over time, and takes into account an objective and subjective assessment of life in physical, psychological and social terms. One of the chronic diseases which results in the reduction of the quality of life is rheumatoid arthritis (RA), one of the most aggressive and most common rheumatic diseases. This is a condition causing chronic inflammation of the bone-joint system, and the result of this process is a permanent deformation of bones and joints along with their damage.

Rheumatoid arthritis is an incurable disease resulting in progressive disability so a social aspect of the disease is increasingly significant, especially when every $3^{\text {rd }}$ person suffering from this condition is not capable of performing any paid work within 2 years from the time of diagnosis. ${ }^{1-3}$ Progressive disability is associated with the loss of productivity, financial burden on the patient's family and the impossibility of earning money. Patients are often not prepared to change their way of life, which is the reason why it is important to make them aware of the significance of active cooperation in therapy. This applies especially to regular exercise at home, adapted to current capabilities, which helps to reduce the motor dysfunction, and the use of dietary therapy. ${ }^{4}$

One of the main problems of people with RA is pain,which undoubtedly is reflected in the mental condition of the patient and their social functioning. Due to the multidimensional character of the disease, it is important for the successful treatment of this patient group to improve mutual communication, engage the patient in the therapy, broaden their knowledge about the disease, which significantly influences the effects of the treatment. ${ }^{5-7}$ The need to undertake educational activities aimed at patients with rheumatoid arthritis comes from the currently biggest challenge of contemporary medicine referring to all chronic diseases - failure in following the therapy guidelines. ${ }^{8,9}$ Knowledge about the disease is the key to achieve the maximum effects of treatment and one of the ways to prevent the consequences of improperly treated disease. ${ }^{10,11}$

It is also essential to enable the patient, through counseling and retraining, to get a suitable employment opportunity, which is the basis for developing an active attitude to life and regaining independence in the later stages of the disease. It is also relevant in the process of accepting the disability and feeling satisfaction from life. ${ }^{12}$
The solution may be the improvement of the therapeutic relationship between the therapeutic team and the patient in order to increase the efficiency of the treatment through better knowledge about the disease, and to reduce the impact of the disease on the mental condition of the patient. ${ }^{13}$

\section{Material and methods}

The study included 270 patients diagnosed with rheumatoid arthritis, treated at the Department of Rheumatology and Internal Medicine (Table 1).

The author's questionnaire, International Questionnaire SF-36 questionnaire, and the General Health Questionnaire GHQ-30 were used to collect the study data.

The author's questionnaire allowed us to gather basic information about the study group and to assess the level of knowledge about RA. ${ }^{14}$

Questionnaire SF-36 estimated the areas included in a wide approach to health definition, covering 8 competent scales defining physical and mental aspects of the quality of life. ${ }^{15}$ These are:

- $\quad$ physical functioning - PF;

- mental health - MH;

- $\quad$ social functioning - SF;

- role physical - RP;

- role emotional - RE;

- vitality - VT;

- general health - GH;

- bodily pain - BP,

Table 1. Characteristics of the study group (data was presented as mean \pm SD).

\begin{tabular}{|c|c|c|c|c|c|}
\hline \multirow{2}{*}{\multicolumn{2}{|c|}{ Variable }} & \multicolumn{4}{|c|}{ Characteristics of the study group } \\
\hline & & entire group & women & men & $p$-value \\
\hline \multicolumn{2}{|c|}{ Number of patients } & $270(100 \%)$ & 195 (77.22\%) & $75(27.78 \%)$ & - \\
\hline \multicolumn{2}{|l|}{$\begin{array}{l}\text { Age } \\
\text { mean } \pm S D\end{array}$} & $56.9 \pm 15.2$ & $57.6 \pm 15.5$ & $55.11 \pm 14.45$ & 0.23 \\
\hline \multirow{4}{*}{ Education } & basic & $28(10.37 \%)$ & $20(10.26 \%)$ & $8(10.67 \%)$ & \multirow{4}{*}{0.001} \\
\hline & vocational & $77(28.52 \%)$ & $43(22.05 \%)$ & $34(45.33 \%)$ & \\
\hline & secondary & $107(39.63 \%)$ & 84 (43.08\%) & 23 (30.67\%) & \\
\hline & higher & $58(21.48 \%)$ & $48(24.62 \%)$ & $10(13.33 \%)$ & \\
\hline \multirow{5}{*}{$\begin{array}{l}\text { Professional } \\
\text { activity }\end{array}$} & work & $66(24.44 \%)$ & $41(21.03 \%)$ & $25(33.33 \%)$ & \multirow{5}{*}{0.06} \\
\hline & retirement pension & $72(26.67 \%)$ & $48(24.62 \%)$ & $24(32 \%)$ & \\
\hline & disability pension & 115 (42.59\%) & $93(47.69 \%)$ & $22(29.33 \%)$ & \\
\hline & benefit & $3(1.11 \%)$ & $2(1.03 \%)$ & $1(1.33 \%)$ & \\
\hline & unemployed & $14(5.19 \%)$ & $11(5.64 \%)$ & $3(4 \%)$ & \\
\hline \multirow{4}{*}{$\begin{array}{l}\text { Duration } \\
\text { of the disease }\end{array}$} & $1-3$ years & $71(26.3 \%)$ & $48(24.62 \%)$ & $23(30.67 \%)$ & \multirow{4}{*}{0.006} \\
\hline & $3-5$ years & $43(15.93 \%)$ & $23(11.79 \%)$ & $20(26.67 \%)$ & \\
\hline & $5-10$ years & $62(22.96 \%)$ & $49(25.13 \%)$ & $13(17.33 \%)$ & \\
\hline & $>10$ years & $94(34.81 \%)$ & 75 (38.46\%) & 19 (25.33\%) & \\
\hline \multicolumn{2}{|c|}{$\begin{array}{l}\text { Duration of the disease }>10 \text { years } \\
\text { mean } \pm S D\end{array}$} & $19.2 \pm 7$ & $18.65 \pm 6.5$ & $21.26 \pm 8.51$ & 0.48 \\
\hline \multicolumn{2}{|c|}{ Disease in the family } & $121(44.81 \%)$ & $96(49.23 \%)$ & $25(33.33 \%)$ & 0.02 \\
\hline
\end{tabular}


Physical Component Summary (PCS) consists of PF, RP, VT, BP. Mental Component Summary (MCS) consists of $\mathrm{MH}, \mathrm{SF}, \mathrm{RE}, \mathrm{GH}$.

Factors of the quality of life were estimated on the basis of the system SF-36, which allowed us to estimate 8domains of life and to calculate on their grounds the level of physical and mental activities depicting the general condition of a patient. The level of physical and mental activities was calculated using the norms assumed for the USA because there are no norms created for Poland and accepted by the QualityMetric, Inc.

Five scales (PF, RP, BP, SF, RE) describe the state of a person's functioning as a lack of limitations or disability. Three of the above mentioned scales (PF, RP, BP) reflect most accurately the physical condition of a patient, but it should be noted that each of them refers to a different aspect thereof. PF measures the constraints of daily physical activity, $\mathrm{RP}$ includes limitations in life, while BP focuses on the pain and the resultant limitations in everyday life.

The most useful in the presentation of the mental functioning of a patient are SF and RE. Their maximum results (100 points) indicate the lack of physical and emotional problems.

Other scales such as MH, VT and GH are bipolar, i.e., they measure both the positive and the negative picture of a patient. For the MH scale, the scoring in the middle of the range (50 points) means the lack of restrictions caused by personal or emotional problems. In the case of achieving the maximum score, it indicates frequently recurring feelings of happiness and peace.

The changes in the physical and mental well-being are detected by VT and GH scales. The middle score on the VT scale means no symptoms of fatigue or exhaustion, while the maximum (100 points) indicates additionally constantly occurring feeling of energy. The middle and higher scores on the GH scale confirm general health. ${ }^{14}$

General Health Questionnaire (GHQ) by David Goldberg is a screening tool used to assess non-specific psychiatric morbidity. The authors of the Polish version of GHQ-30 are Krzysztof Małyszczak and Stanisław Sidorowicz. ${ }^{16}$ The test assesses the current psychiatric condition and is used to identify the cases which are at a significant likelihood of developing disorders. The overall score of the questionnaire is influenced by individual sensibility, a way of going through and feeling during the course of disease. Therefore it is believed that using GHQ can also help to measure the condition of mental disorder and a subjective evaluation of its consequences, which is called a non-specific psychiatric morbidity. This study used a version of the questionnaire with 30 questions (GHQ-30). The maximum score a patient can get is 30 points. The threshold of 5 points provides a basis for the identification of persons with mental disorders. The study used a scoring method by Goldberg: $0-0-1-1$. The questionnaire can be treated, on one hand, as a 1-dimensional tool; on the other hand, it would be reasonable to isolate specific factors, which are called: anxiety and depression, interpersonal relations and general functioning.

The statistical analysis was performed using the program STATISTICA v. 10 PL with the application of Student's t-test and $X^{2}$ test. The level of significance was set at $\mathrm{p}=0.05$.

The analysis of the impact of independent variables (covariates) on the level of quality of life in patients with rheumatoid arthritis was conducted through a multiple regression analysis. The model takes into account the following factors:

- X1: age;

- X2: gender (1 - woman; 0 - man);

- X3: place of residence (0 - village; 1 - city);

- X4: vocational education $(0-$ no; 1 - yes);

- X5: secondary education ( 0 - no; 1 - yes);

- X6: higher education (0 - no; 1 - yes);

- X7: professional activity (0 - no; 1 - yes);

- X8: professional activity - disability pension (0 - no; 1 - yes);

- X9: professional activity - pension ( 0 - no; 1 - yes);

- X10: professional activity - unemployed (0 - no; 1 - yes);

- X11: duration of disease $1-3$ years $(0-$ no; 1 - yes);

- X12: duration of disease $5-10$ years $(0-$ no; $1-$ yes);

- X13: duration of disease $>10$ years $(0-$ no; $1-$ yes $)$;

- X14: disease in the family (0 - no; 1 - yes);

- X15: preventing procedures - regular medication (0 - no; 1 - yes);

- X16: preventing procedures - gymnastics (0 - no; 1 - yes);

- X17: lack of preventing procedures - smoking cigarettes ( 0 - no; 1 - yes);

- X18: preventing procedures - healthy diet (0 - no; 1 - yes);

- X19: medical consultation once a year (0 - no; 1 - yes);

- X20: medical consultation twice a year (0 - no; 1 - yes);

- X21: medical consultation more than twice a year (0 - no; 1 - yes);

- X22: hospitalization once a year (0 - no; 1 - yes);

- X23: hospitalization twice a year (0 - no; 1 - yes);

- X24: sources of knowledge - doctor ( 0 - no; 1 - yes);

- X25: sources of knowledge - physiotherapist (0 - no; 1 - yes);

- X26: sources of knowledge - nurse (0 - no; 1 - yes);

- X27: sources of knowledge - books ( 0 - no; 1 - yes);

- X28: sources of knowledge - medical journals (0 - no; 1 - yes);

- X29: sources of knowledge - journals (0 - no; 1 - yes);

- X30: sources of knowledge - television (0 - no; 1 - yes);

- X31: sources of knowledge - internet (0 - no; 1 - yes); 
- $\quad \mathrm{X} 32$ : sources of knowledge - colleagues ( 0 - no; 1 - yes);

- X33: subjective estimation of the level of knowledge $(0-10)$;

- X34: difficulties in education - lack of time (0 - no; 1 - yes);

- X35: difficulties in education - lack of interest (0 - no; 1 - yes);

- X36: difficulties in education - lack of financial possibilities ( 0 - no; 1 - yes);

- X37: difficulties in education - lack of place ( 0 - no; 1 - yes);

- X38: difficulties in education - poor preparation (0 - no; 1 - yes);

- X39: subjective health condition - good $(0-$ no; $1-$ yes);

- X40: subjective health condition - not bad (0 - no; 1 - yes);

- X41: subjective estimation of health - bad ( 0 - no; 1 - yes);

- X42: state of knowledge - symptoms of disease (point);

- X43: state of knowledge - rehabilitation and pharmacological treatment (point);

- $\mathrm{X} 44$ : state of knowledge - prevention and leisure (point);

- X45: state of knowledge - general state of knowledge (point);

- X46: a feeling that life is not worth living (1 - not at all; 2 - not more than usual; 3 - a bit more than usual; 4 - a lot more than usual);

- X47: symptoms of anxiety and depression GHQ-30 (points);

- X48: interpersonal relations GHQ-30 (points);

- X49: overall functioning GHQ-30 (points);

- X50: overall result of the health GHQ-30 (points).

\section{Results}

The analysis of the study material showed that there were no statistically significant differences in particular domains of the SF-36 questionnaire in terms of gender (Table 2).

A multiple regression analysis of the impact of independent variables on the quality of life in patients with RA has yielded the following results:

- the level of physical functioning $(\mathrm{PF})$ is positively affected by active professional work $(\mathrm{p}=0.002)$, higher education ( $p=0.004)$ and the acquisition of knowledge about the disease from friends $(\mathrm{p}=0.01)$, and is negatively affected by age ( $\mathrm{p}=0.001)$, lack of education ( $\mathrm{p}=0.004)$, low subjective state of knowledge about the disease $(\mathrm{p}=0.004)$ and poor subjective health (SF-36) $(\mathrm{p}<0.001)$ (Table 3$)$;

- limited activity due to physical health (RP) is mostly influenced by the interpersonal relationships (GHQ30) $(\mathrm{p}=0.002)$, the general level of health (GHQ-30) $(\mathrm{p}=0.001)$ and subjective health condition (SF-36) $(\mathrm{p}<0.001)$;

- the level of pain (BP) depends on interpersonal relationships (GHQ-30) ( $\mathrm{p}=0.019)$, the general health $(\mathrm{GHQ}-30)(\mathrm{p}<0.001)$ and subjective health status (SF-36) $(\mathrm{p}=0.004)$;

- the general perception of health $(\mathrm{GH})$ is positively influenced by the acquisition of knowledge from nurses $(\mathrm{p}=0.02)$, and is negatively affected by age $(\mathrm{p}=0.005)$ and the presence of RA history in the family $(\mathrm{p}=0.001)$ (Table 4$)$;

- the level of vitality (VT) is positively influenced by the acquisition of knowledge from a physiothera-

Table 2. The analysis of factors related to quality of life - SF-36

\begin{tabular}{|c|c|c|c|c|}
\hline \multirow{2}{*}{ Factors related to quality of life - SF-36 } & \multicolumn{4}{|c|}{ Study group } \\
\hline & entire group & women & men & $\mathrm{p}$-value \\
\hline Number of patients & $270(100 \%)$ & $195(77.22 \%)$ & $75(27.78 \%)$ & \\
\hline $\begin{array}{l}\text { Subjective health condition } \\
\text { perfect } \\
\text { very good } \\
\text { good } \\
\text { not bad } \\
\text { bad }\end{array}$ & $\begin{array}{c}0 \\
2(0.74 \%) \\
34(12.59 \%) \\
114(42.22 \%) \\
120(44.44 \%)\end{array}$ & $\begin{array}{c}0 \\
2(1.03 \%) \\
25(12.82 \%) \\
76(38.97 \%) \\
92(47.18 \%)\end{array}$ & $\begin{array}{c}0 \\
0 \\
9(12 \%) \\
38(50.67 \%) \\
28(37.33 \%)\end{array}$ & 0.29 \\
\hline Subjective health state [points (0-100)] mean \pm SD & $18.86 \pm 20.75$ & $18.43 \pm 21.35$ & $19.99 \pm 19.2$ & 0.58 \\
\hline Physical functioning (PF) [points] mean \pm SD & $33.69 \pm 25$ & $31.85 \pm 24.73$ & $38.47 \pm 25.24$ & 0.051 \\
\hline Limited activity due to role physical (RP) [points] mean $\pm \mathrm{SD}$ & $9.44 \pm 25.84$ & $9.23 \pm 25.35$ & $10 \pm 27.26$ & 0.83 \\
\hline Bodily pain (BP) [points] mean $\pm S D$ & $26.18 \pm 18.9$ & $26.84 \pm 19.84$ & $25.01 \pm 16.25$ & 0.53 \\
\hline General health $(\mathrm{GH})$ [points] mean $\pm \mathrm{SD}$ & $19.23 \pm 13.33$ & $19.05 \pm 13.86$ & $19.71 \pm 11.91$ & 0.72 \\
\hline Vitality (VT) [points] mean $\pm S D$ & $35.31 \pm 11.34$ & $34.95 \pm 10.48$ & $36.27 \pm 13.36$ & 0.39 \\
\hline Social functioning (SF) [points] mean $\pm S D$ & $44.77 \pm 25.09$ & $44.62 \pm 25.76$ & $45.17 \pm 23.42$ & 0.87 \\
\hline Limited activity due to role emotional (RE) [points] mean $\pm S D$ & $53.95 \pm 48.59$ & $51.45 \pm 48.72$ & $60.44 \pm 47.99$ & 0.17 \\
\hline Mental health $(\mathrm{MH})$ [points] mean $\pm \mathrm{SD}$ & $51.29 \pm 16.9$ & $51.2 \pm 17.11$ & $51.52 \pm 16.43$ & 0.89 \\
\hline Physical component summary (PCS) [points] mean \pm SD & $24.18 \pm 7.52$ & $24.01 \pm 7.71$ & $24.63 \pm 7.03$ & 0.54 \\
\hline Mental component summary (MCS) [points] mean \pm SD & $42.66 \pm 10.35$ & $42.42 \pm 10.5$ & $43.28 \pm 9.99$ & 0.55 \\
\hline
\end{tabular}


pist ( $\mathrm{p}<0.001)$, a medical journal $(\mathrm{p}=0.004)$ or the Internet $(\mathrm{p}=0.005)$, whereas it is negatively affected by a low level of health (GHQ-30) ( $<<0.001)$;

- the level of social functioning (SF) is positively influenced by good subjective health condition (SF-36 $(p=0.002)$, whereas it is negatively affected by a feeling that life is not worth living (GHQ-30) $(\mathrm{p}=0.027)$ and a low level of health (GHQ-30) $(\mathrm{p}=0.00)$ (Table 5);

- role emotional (RE) depends on the frequency of medical consultations (more than twice a year) ( $\mathrm{p}=0.003)$;

- the level of mental health (MH) is positively influenced by a low level of symptoms of anxiety and depression (GHQ-30) ( $\mathrm{p}=0.014)$, whereas it is negatively affected by a positive family history $(\mathrm{p}=0.007)$ and poor subjective health (SF-36) $(\mathrm{p}=0.005)$;

- the level of PCS is positively influenced by declared very good health condition (SF-36) ( $p=0.037)$, whereas it is negatively affected by the age factor $(\mathrm{p}<0.001)$;

- the level of MCS is positively influenced by frequent medical consultations $(\mathrm{p}=0.004)$, whereas it is negatively affected by a positive family history of RA $(\mathrm{p}=0.009)$, poor subjective health $(\mathrm{p}=0.015)$ and a low level of health according to GHQ-30 ( $<<0.001)$.

The analysis of the study material obtained from the GHQ-30 questionnaire showed that particular domains did not show any statistically significant differences in terms of gender (Table 6).

A multiple regression analysis of the impact of independent variables on the health levels in RA patients has yielded the following results:

- symptoms of anxiety and depression are negatively affected by the occurrence of disease (RA) in the family, rare medical consultations and a feeling that life is not worth living;

Table 3. Summing up of changeable dependable regression concerning physical functioning $(R 2=0.594)$

\begin{tabular}{|l|c|c|c|}
\hline \multicolumn{1}{|c|}{ Factors } & $\beta$ & $\mathrm{b}$ & $\mathrm{p}$-value \\
\hline Age & -0.28 & -0.47 & $<0.001$ \\
\hline Vocational education & 0.19 & 10.77 & 0.004 \\
\hline Secondary education & 0.17 & 8.49 & 0.021 \\
\hline Higher education & 0.19 & 11.62 & 0.004 \\
\hline Professional activity - work & 0.14 & 8.01 & 0.002 \\
\hline Source of knowledge - friends & 0.11 & 7.51 & 0.01 \\
\hline Subjective evaluation of the knowledge level & -0.12 & -1.72 & 0.004 \\
\hline General functioning (GHQ-30) & -0.12 & -1.10 & 0.014 \\
\hline Subjective health condition - not bad & -0.29 & -14.79 & $<0.001$ \\
\hline Subjective health condition - bad & -0.59 & -29.70 & $<0.001$ \\
\hline
\end{tabular}

The designated method of least squares model of physical functioning takes the following form: $\mathrm{PF}=80.88-0.47 \times \mathrm{X} 1+10.77 \times \mathrm{X} 4+8.49 \times \mathrm{X} 5+$ $11.62 \times X 6+8.01 \times X 7+7.51 \times X 32-1.72 \times X 33-14.79 \times X 40-29.7 \times X 41$ $-1.1 \times X 49 \pm 16.23 ; R 2=0.594 ; \beta$ - variable importance factor; $b$ - variable coefficient $(y=b x+c) ; p$ - level of significance; $R 2$ - relevance factor; $c$ - standard error of estimate $(y=b x \pm c)$.
- interpersonal relationships are positively influenced by higher education ( $p=0.036)$, place of residence - a city $(\mathrm{p}=0.009)$ and a shorter duration of disease $-1-3$ years $(\mathrm{p}=0.001)$, and are negatively affected by a positive family history of RA $(p=0.026)$ and a feeling that life is not worth living $(\mathrm{p}<0.001)$;

- general functioning is positively influenced by a higher education $(\mathrm{p}=0.002)$ and reading books about the disease ( $p=0.0011)$, whereas it is negatively affected by age $(\mathrm{p}=0.004)$, the presence of the disease in the family $(\mathrm{p}=0.012)$ and a feeling that life is not worth living $(\mathrm{p}<0.001)$;

- general health (GHQ-30) is positively affected by education ( $p=0.003)$, place of residence - a city $(p=0.013)$, active professional work ( $\mathrm{p}=0.001)$, whereas it is negatively affected by a positive family history of RA $(\mathrm{p}=0.002)$, frequent stays in the hospital $(\mathrm{p}=0.008)$ and poor subjective health status $(\mathrm{p}<0.001)$ (Table 7$)$.

Table 4. Summing up of changeable dependable regression concerning general health perception $(R 2=0.443)$

\begin{tabular}{|l|c|c|c|}
\multicolumn{1}{|c|}{ Factors } & $\beta$ & $\mathrm{b}$ & $\mathrm{p}$-value \\
\hline Age & -0.14 & -0.13 & 0.005 \\
\hline Disease in the family & -0.15 & -4.12 & 0.001 \\
\hline Source of knowledge - nurse & 0.11 & 4.96 & 0.02 \\
\hline Difficulties in obtaining education - lack of time & -0.14 & -4.10 & 0.006 \\
\hline Difficulties in education - lack of interest & 0.10 & 2.92 & 0.042 \\
\hline Subjective health condition - not bad & -0.52 & -14.10 & $<0.001$ \\
\hline Subjective health condition - bad & -0.70 & -18.82 & $<0.001$ \\
\hline
\end{tabular}

The designated method of least squares model of general health perception takes the following form: $\mathrm{GH}=46.44-0.13 \times \mathrm{X} 1-4.12 \times \mathrm{X} 14$ $+4.96 \times \times 26-4.1 \times \times 34+2.92 \times \times 35-14.1 \times \times 40-18.82 \times \times 41-0.17$ $\times X 50 \pm 10.1 ; R 2=0.443 ; \beta$ - variable importance factor; $b$ - variable coefficient $(y=b x+c) ; p$ - level of significance; $R 2$ - relevance factor; $c$ standard error of estimate

$(y=b x \pm c)$.

Table 5. Summing up of changeable dependable regression concerning social functioning $(R 2=0.49)$

\begin{tabular}{|l|c|c|c|}
\multicolumn{1}{|c|}{ Factors } & $\beta$ & $\mathrm{b}$ & $\mathrm{p}$-value \\
\hline Sources of knowledge - books & -0.11 & -5.97 & 0.017 \\
\hline Sources of knowledge - medical papers & 0.09 & 7.69 & 0.045 \\
\hline Feeling that life is not worth living & -0.12 & -3.73 & 0.027 \\
\hline Interpersonal relationships (GHQ-30) & 0.32 & 4.41 & 0.004 \\
\hline General health (GHQ-30) & -0.80 & -2.00 & 0.000 \\
\hline Subjective health condition - not bad & -0.15 & -7.77 & 0.028 \\
\hline Subjective health condition - bad & -0.24 & -11.96 & 0.002 \\
\hline Subjective health condition - not bad & 0.10 & 1.72 & 0.035 \\
\hline
\end{tabular}

The designated method of least squares model of social functioning takes the following form: $\mathrm{SF}=72.41-5.97 \times \mathrm{X} 27+7.69 \times \mathrm{X} 28-7.77 \times$ $X 40-11.96 \times X 41+1.72 \times X 43-3.73 \times X 46+4.41 \times X 48-2 \times X 50 \pm 18.05 ;$ $\mathrm{R} 2=0.49 ; \beta$ - variable importance factor; $b$ - variable coefficient $(y=b x+c) ; p$ - level of significance; $R 2$ - relevance factor;

$c$ - standard error of estimate $(y=b x \pm c)$. 


\section{Discussion}

A crucial element in the treatment and rehabilitation of patients with rheumatoid arthritis should be the analysis of quality of life. Due to the fact that it is a chronic, progressive and still incurable disease, care should be taken to improve the viability of patients by means of a thorough examination of the factors that impair their quality of life. In addition, continuously developing knowledge on the quality of life of patients with RA should help to eliminate the factors that have the most negative impact on the various spheres of life of such patients.

Our study confirmed that patients suffering from RA are characterized by low quality of life both in the domain of PCS and in the domain of MCS. ${ }^{17-24}$ The lower number of points in the PCS domain in comparison to the MCS domain may indicate that RA affects more the physical than the mental sphere as indicated by other authors. ${ }^{21,23,24}$

It was also shown that the quality of life of patients with RA depends on many factors of physical, mental and social functioning sphere. ${ }^{17,19-21,23-31}$

Studies conducted by many authors have shown that poorer functioning of the respondents in the physical sphere is conditioned by the duration of the disease. ${ }^{18,24,26,28,30}$ Studies by Baloglu et al. and Wisłowska et al. did not confirm this dependence. ${ }^{20,31}$ In our study, the worse results in the PF domain and the PCS scale were related to age of the respondents, which has also been indicated by other authors. ${ }^{20,23,31}$ It was also shown that people who subjectively assessed their health as poor had a lower perception of the quality of their lives in the domains of physical activity (PF, RP and BP) as well.

The literature highlights the fact that quality of life is modified by patients' convictions about their health, which is reflected in the results of our own study, where people with poor subjective health condition were characterized by greater limitations of activity due to physical health and lower general health (GHQ-30). ${ }^{30}$

The studies by van Vilsteren et al. concluded that patients suffering from RA with low quality of life are characterized by decreased productivity. ${ }^{26}$ Our study showed that economic activity has a positive effect on the general health level according to GHQ-30.

Factors such as higher education and living in a city also had a positive effect on general health (GHQ-30).

The results obtained from the SF-36 questionnaire and GHQ-30 revealed the occurrence of symptoms such as anxiety and depression and a decreased quality of life in the MCS domain. Rheumatoid arthritis is undoubtedly a disease which leaves permanent consequences of a psychological nature, especially in the emotional area, and affects quality of life. ${ }^{17,20,29}$ There are many premises suggesting that personal predispositions of a patient, their competence and approach to the disease may have a considerable influence on the further course of the disease and its prognoses. According to Abu Al-Fadl et al. and Maiden et al., during the treatment of patients with RA, more attention should be paid to the identification of symptoms of depression because the emotional condition affects the quality of life of patients and treatment outcomes. ${ }^{17,32}$

Frequent contact with the members of the therapeutic team and obtaining accurate information positively affected the selected domains (GH, VT, RE, MCS) in RA patients, which was presented for the first time in our study and proves the need for providing informational and emotional support by the members of the therapeutic team.

It was also shown that interpersonal relationships affected activity limitations due to physical health (RP), the level of pain (BP) and the level of social functioning (SF). This means that people with satisfying relationships with others less frequently experienced limitations in the sphere of physical activity and experienced less pain, and better functioned in the society.

Mäkeläinen et al. attempted to find an answer to the question if there is a dependence between the level of knowledge in 252 patients with rheumatoid arthritis and their physical functioning. ${ }^{33}$ The studies did not reveal a correlation between the level of knowledge of patients and their physical functioning in everyday life. The autors' own study showed, however, that the level of knowledge about the disease affected the SF domain in the SF-36 questionnaire.

The evaluation of quality of life has an enormous significance in economic analyses. Financing health care, costs of treatment, its effectiveness are the leading subjects. We need to find an answer to the question if the treatment means applied for this purpose correlate with the effects, patient satisfaction and the level of quality of life. ${ }^{34}$

The quality of life of patients suffering from rheu- 
Table 7. Summary of changeable dependable regression concerning general health $(\mathrm{GHQ}-30)(\mathrm{R} 2=0.41)$

\begin{tabular}{|l|c|c|c|}
\multicolumn{1}{|c|}{ Factors } & $\beta$ & $\mathrm{b}$ & $\mathrm{p}$-value \\
\hline Place of residence & -0.13 & -3.05 & 0.013 \\
\hline Secondary education & -0.17 & -3.38 & 0.002 \\
\hline Higher education & -0.17 & -4.08 & 0.003 \\
\hline Professional activity - work & -0.19 & -4.27 & 0.001 \\
\hline Professional activity - disability pension & -0.17 & -3.76 & 0.002 \\
\hline History of RA in the family & 0.15 & 3.01 & 0.002 \\
\hline Hospitalization twice a year & 0.13 & 3.65 & 0.008 \\
\hline Source of knowledge - books & -0.11 & -2.34 & 0.031 \\
\hline Subjective health condition - good & -0.34 & -10.29 & $<0.001$ \\
\hline Subjective health condition - not bad & -0.41 & -8.10 & $<0.001$ \\
\hline
\end{tabular}

The designated method of least squares model of general health (GHQ-30) takes the following form: $\mathrm{GH}=22.79-3.05 \times \mathrm{X} 3-3.38 \times \times 5-$ $4.08 \times X 6-4.27 \times X 7-3.76 \times X 8+3.01 \times X 14+3.65 \times X 23-2.34 \times X 27$ $-10.29 \times X 39-8.1 \times X 40 \pm 7.76 ; R 2=0.41 ; \beta$ - variable importance factor $b$ - variable coefficient $(y=b x+c) ; p$ - level of significance; $R 2$ - relevance factor; $c$ - standard error of estimate $(y=b x \pm c)$

matoid arthritis is determined by psycho-physical activities and many other factors. It is promising that there are more and more studies on the quality of life in rheumatoid diseases. The conducted research and the results of our own study showed that the International Questionnaire - SF-36 and the General Health Questionnaire GHQ-30 are good tools to assess the quality of life in patients with rheumatoid arthritis and help to identify therapeutic strategies aimed at minimizing the deficits in the area of emotional support and education in patients with RA. ${ }^{23,31,35}$

\section{Conclusions}

Physical activity of patients with rheumatoid arthritis depends on their age and subjective health condition. General health (GHQ-30) in patients with rheumatoid arthritis is influenced by education, place of residence, professional work, family history of RA and subjective health status. Frequent contact and accurate information obtained from the members of the therapeutic team has a positive effect on the selected domains of quality of life in patients with RA. The SF-36 scale and the GHQ-30 questionnaire may be used at the time of hospitalizations at the rheumatoid ward as methods of detecting patients with possible risk of emotional disorders and disorders in social functioning.

\section{References}

1. Benucci M, Rogai V, Atzeni F, Hammen V, Sarzti-Puttini P, Migliore A. Costs associated with rheumatoid arthritis in Italy: Past, present, and future. Clin Outcomes Res CEOR. 2016;8:33-41.

2. Talotta R, Berzi A, Atzeni F, et al. Paradoxical expansion of Th1 and Th17 lymphocytes in rheumatoid arthritis following infliximab treatment: A possible explanation for a lack of clinical response. J Clin Immunol. 2015;35:550-557.
3. Colebatch-Bourn AN, Edwards CJ, Collado P, et al. EULAR-PReS points to consider for the use of imaging in the diagnosis and management of juvenile idiopathic arthritis in clinical practice. Ann Rheum Dis. 2015;74:1946-1957.

4. Peng J, Gong Y, Zhang Y, Xiao Z, Zeng Q, Chen S. Bone mineral density in patients with rheumatoid arthritis and 4-year followup results. J Clin Rheumatol Pract Rep Rheum Musculoskelet Dis. 2016;22:71-74.

5. van der Woude D, Toes REM, Scherer HU. How undifferentiated arthritis evolves into chronic arthritis. Best Pract Res Clin Rheumatol. 2014;28:551-564.

6. Tsai $C L$, Lin $C F$, Lin $H T$, et al. How kinematic disturbance in the deformed rheumatoid thumb impacts on hand function: A biomechanical and functional perspective. Disabil Rehabil. 2016;1-8.

7. Moreira E, Jones A, Oliveira HA, Jennings F, Fernandes A, Natour J. Effectiveness of insole use in rheumatoid feet: A randomized controlled trial. Scand J Rheumatol. 2016;1-8.

8. Larsson I, Fridlund B, Arvidsson B, Teleman A, Svedberg P, Bergman S. A nurse-led rheumatology clinic versus rheumatologist-led clinic in monitoring of patients with chronic inflammatory arthritis undergoing biological therapy: A cost comparison study in a randomised controlled trial. BMC Musculoskelet Disord. 2015;16:354.

9. Uutela $T$, Kautiainen $H$, Järvenpää S, Hakala M, Häkkinen A. Self-rated health in patients with rheumatoid arthritis is associated with health-related quality of life but not with clinical variables. Scand J Rheumatol. 2016;45:288-293.

10. Nüßlein HG, Alten R, Galeazzi M, et al. Efficacy and prognostic factors of treatment retention with intravenous abatacept for rheumatoid arthritis: 24-month results from an international, prospective, real-world study. Clin Exp Rheumatol. 2016;34:489-499.

11. Jennings F, Toffolo S, de Assis MR, Natour J. Brazil Patient Knowledge Questionnaire (PKQ) and evaluation of disease-specific knowledge in patients with rheumatoid arthritis. Clin Exp Rheumatol. 2006;24:521-528.

12. Nawata M, Saito K, Fukuyo S, Hirata S, Tanaka Y. Clinically relevant radiographic progression in joint destruction in $\mathrm{RA}$ patients with abnormal MMP-3 or high levels of CRP despite 1-year treatment with infliximab. Mod Rheumatol Jpn Rheum Assoc. 2016;26:807-812.

13. Sparks JA, Chang SC, Deane KD, et al. Associations of smoking and age with inflammatory joint signs among first-degree relatives without rheumatoid arthritis: Results from the studies of the etiology of RA. Arthritis Rheumatol. 2016;68:1828-1838.

14. Pytel A, Wrzosek Z. Estimation of patient knowledge on rheumatoid arthritis in the range of their own disease-preliminary study. Adv Clin Exp Med Off Organ Wroclaw Med Univ. 2012;21:343-351.

15. McHorney CA, Ware JE, Raczek AE. The MOS 36-Item Short-Form Health Survey (SF-36): II. Psychometric and clinical tests of validity in measuring physical and mental health constructs. Med Care. 1993;31:247-263.

16. Frydecka D, Małyszczak K, Chachaj A, Kiejna A. Struktura czynnikowa Kwestionariusza Ogólnego Zdrowia (GHQ-30). Psychiatr Pol. 2010;44:341-351.

17. Abu Al-Fadl EM, Ismail MA, Thabit M, El-Serogy Y. Assessment of health-related quality of life, anxiety and depression in patients with early rheumatoid arthritis. Egypt Rheumatol. 2014;36:51-56.

18. West $E$, Jonsson SW. Health-related quality of life in rheumatoid arthritis in Northern Sweden: A comparison between patients with early RA, patients with medium-term disease and controls, using SF-36. Clin Rheumatol. 2005;24:117-122.

19. Azevedo AF, Petribú KC, Lima Mde N, et al. Quality of life of patients with rheumatoid arthritis under biological therapy. Rev Assoc Médica Bras. 2015;61:126-131.

20. Baloglu $\mathrm{HH}$, Askin A, Yener M. Determination of the factors that affect health-related quality of life in patients with rheumatoid arthritis. Acta Medica Mediterr. 2015;31:687-695.

21. Gong G, Mao J. Health-related quality of life among Chinese patients with rheumatoid arthritis: The predictive roles of fatigue, functional disability, self-efficacy, and social support. Nurs Res. 2016;65:55-67.

22. Jankowska-Polańska B, Nawrocka A, Uchmanowicz I, Rosińczuk J, Polański J. Quality of life and methods of coping with stress depending on the used form of therapy of rheumatoid arthritis treatment. Prog Health Sci. 2014;4:102-110. 
23. Matcham F, Scott IC, Rayner L, et al. The impact of rheumatoid arthritis on quality-of-life assessed using the SF-36: A systematic review and meta-analysis. Semin Arthritis Rheum. 2014;44:123-130.

24. Wysocka-Skurska I, Sierakowska M, Kułak W. Evaluation of quality of life in chronic, progressing rheumatic diseases based on the example of osteoarthritis and rheumatoid arthritis. Clin Interv Aging. 2016;11:1741-1750.

25. Jankowska B, Uchmanowicz I, Polański J, Uchmanowicz B. Czynniki kliniczne i socjodemograficzne determinujące jakość życia w reumatoidalnym zapaleniu stawów. Fam Med Prim Care Rev. 2010;12:1027-1034.

26. van Vilsteren $M$, Boot $C R$, $K n o l ~ D L$, et al. Productivity at work and quality of life in patients with rheumatoid arthritis. BMC Musculoskelet Disord. 2015;16:107.

27. Moćko J, Zurzycka P. Jakość życia pacjentów z reumatoidalnym zapaleniem stawów - doniesienia wstępne. Pielęgniarstwo XXI Wieku. 2013;1:15-19.

28. Haroon N, Aggarwal A, Lawrence A, Agarwal V, Misra R. Impact of rheumatoid arthritis on quality of life. Mod Rheumatol Jpn Rheum Assoc. 2007;17:290-295.

29. Wan SW, He HG, Mak A, et al. Health-related quality of life and its predictors among patients with rheumatoid arthritis. Appl Nurs Res. 2016;30:176-183.

30. Sierakowska M, Matys A, Kasior A, et al. Ocena jakości życia pacjentów z reumatoidalnym zapaleniem stawów. Reumatologia. 2006;44:298-303.

31. Wisłowska M, Kanecki K, Tyszko P, Kapała M. Jakość życia zależna od zdrowia u pacjentów z reumatoidalnym zapaleniem stawów. Reumatologia. 2010;48:104-111.

32. Maiden NL. Quantifying the burden of emotional ill-health amongst patients referred to a specialist rheumatology service. Rheumatology. 2003;42:750-757.

33. Mäkeläinen $P$, Vehviläinen-Julkunen $K$, Pietilä $A M$. Rheumatoid arthritis patients' knowledge of the disease and its treatments: A descriptive study. Musculoskeletal Care. 2009;7:31-44.

34. Ruszkowski J, Leśniowska J. Rzeczywiste, ekonomiczne koszty choroby w Polsce. Pol Stow Zarządznia Wiedzq Ser Stud Mater. 2010;25:244-256.

35. Michaud K, Bombardier C, Emery P. Quality of life in patients with rheumatoid arthritis: Does abatacept make a difference? Clin Exp Rheumatol. 2007;25:S35-45. 